\title{
Efeito da Herança Citoplasmática sobre Características de Produção em Ovinos da Raça Merino ${ }^{1}$
}

\section{Octávio Rossi de Morais², José Aurélio Garcia Bergmann³, Daniel Benitez Ojeda, Cleusa Graca da Fonseca ${ }^{5}$, Pedro Franklin Barbosa ${ }^{6}$}

\begin{abstract}
RESUMO - Para avaliar os efeitos de linhagem citoplasmática (LCT), foram usadas medidas de peso corporal (PC, $\mathrm{n}=707)$ e peso de velo sujo (PVo, $n=703$ ) de fêmeas e medidas de diâmetro das fibras de lã (DF, $n=350$ ) de machos ovinos da raça Merino com um ano de idade. As informações de pedigree incluíram 3645 animais e, em média, 10 gerações. Foram usados a metodologia da Máxima Verossimilhança Restrita e o modelo animal que incluiu efeito genético direto, efeitos direto e de LCT, efeitos direto, materno e de LCT e efeitos direto, materno e permanente de meio materno. Efeitos fixos de ano e época de nascimento foram incluídos em todos os modelos. O teste da razão das verossimilhanças foi usado para comparar os modelos matemáticos. Não houve diferenças entre os modelos em que se incluiu ou não o efeito de LCT, indicando que os efeitos citoplasmáticos não foram importantes para as características estudadas. Para PC, os resultados indicaram haver confundimento parcial entre os efeitos genético aditivo materno, permanente de meio materno e de LCT. A importância relativa dos efeitos aditivos maternos foi maior para a característica PC (24,2\%, no modelo mais simples; $7,9 \%$ no modelo mais completo) que para PVo e DF. A importância relativa dos efeitos aditivos diretos foi também maior para PC $(24,5$ a $37,1 \%$, para os diferentes modelos), seguido de PVo (de 19,5 a 24,6\%) e DF (de 16,3 a 21,0\%). As estimativas de herdabilidade indicam que a seleção pode ser realizada com sucesso para as características peso corporal, peso de velo sujo e diâmetro das fibras de lã dos ovinos da raça Merino.
\end{abstract}

Palavras-chave: diâmetro das fibras de lã, efeito materno, herança mitocondrial, linhagem citoplasmática, peso corporal, peso do velo

\section{Effects of Cytoplasm Inheritance on Production Traits of Merino Sheep}

ABSTRACT - To evaluate the effects of cytoplasm lineage (CL) the body weight (BW, $\mathrm{n}=707)$ and greasy fleece weight $(\mathrm{FW}, \mathrm{n}=703$ ) of females and fiber wool diameter (FD, $\mathrm{n}=350$ males) of males sheep from yearling Merino sheep were used. The pedigree information included 3,645 animals and an average of 10 generations. The Maximum Restricted Likelihood methodology and animal models that included the direct genetic, direct and CL effects, direct, maternal and CL effects and direct, maternal, environmental maternal effects were used. Fixed effects of year and season of birth were included in all models. The likelihood ratio test was used for comparisons between the models. There were no differences between models including or not CL, indicating that CL effects were not important for the studied traits. For BW, the results indicated a partial confounding among the maternal additive genetic, environmental maternal and CL effects. The importance of maternal additive effects was greater for the BW traits (from $24.5 \%$ at least to $7.9 \%$ in the most comprehensive models) than for FW and FD. The relative importance of direct additive effects was also greater for BW (from 24.5 to $37,1 \%$, for the different models), followed by FW (from 19.5 to 24.6\%) and for FD (from16.3 to 21.0\%). The heritability estimates indicated that the successful selection could be obtained for body weight, fleece weight ad fiber wool diameter of sheep Merino breed.

Key Words: fiber diameter, maternal effect, mitochondrial inheritance, cytoplasm lineage, body weight, fleece weight

\section{Introdução}

Na formação do zigoto, ocorre a complementação do genoma do novo indivíduo, que terá a metade de seu patrimônio genético vinda do pai, e outra metade vinda da mãe. Esta afirmação seria verdadeira, não fosse o fato de que as mitocôndrias, além de possuírem seu próprio código genético, nos mamífe- ros são herdadas somente pelo lado materno. Este tipo de herança uniparental ocorre porque somente o óvulo contribui com porção citoplasmática na formação do zigoto. Isto faz com que, de modo geral, possase dizer que o DNA mitocondrial (mtDNA) de determinado indivíduo é cópia do mtDNA de sua mãe.

Ainda que muito estudado do ponto de vista molecular, o mtDNA e seus produtos têm recebido

\footnotetext{
1 Trabalho realizado com o apoio da CAPES, CNPq, FAPEMIG, FEPMVZ.

2 Professor, Escola de Veterinária da FIPLAC - Valparaíso de Goiás.

${ }^{3}$ Professor, Escola de Veterinária da Universidade Federal de Minas Gerais - Caixa postal, 567 - 30.161.970 - Belo Horizonte, MG.

${ }^{4}$ Diretor Técnico, ARCO - Associação Brasileira de Criadores de Ovinos.

5 Professor do Instituto de Ciências Biológicas da UFMG.

${ }^{6}$ Pesquisador da EMBRAPA/CPPSE.
} 
discreta atenção como fonte de variação das produções dos animais domésticos. Para MIKAMI et al. (1991), a investigação dos efeitos citoplasmáticos justifica-se em todos os tipos de exploração animal, uma vez que o mtDNA produz proteínas envolvidas na atividade respiratória mitocondrial, que podem incrementar funções metabólicas celulares e promover aumento da produção.

Um dos primeiros trabalhos a confirmar a herança citoplasmática como fonte significativa de variação foi o de BELL et al. (1985). Alguns trabalhos subsequientes a este confirmaram, e tantos outros refutaram, seus achados. Embora as divergências de resultados e opiniões pareçam ter sido mais um problema de adequação de pacotes e modelos estatísticos, faz-se importante ressaltar que trabalhos que consideraram os polimorfismos no mtDNA para identificar as linhagens citoplasmáticas e, portanto, certamente trabalhando com linhagens distintas encontraram efeito significativo de linhagem sobre a produção.

Apesar de o genoma mitocondrial ovino estar bem estudado e completamente seqüenciado(HIENDLEDER et al.,1991; VILLALTA et al., 1992), são poucos e recentes os trabalhos que procuram identificar efeitos de herança citoplasmática nas diversas características da ovinocultura. Assim, HIENDLEDER (1996) encontrou efeitos significativos do mtDNA sobre o peso ao nascer de cordeiros da raça Merinolandschaf. No Brasil, até o presente, não foram encontradas citações sobre os efeitos do genoma mitocontrial sobre características de produção dos ovinos.

O objetivo deste trabalho foi verificar a importância da inclusão de linhagem citoplasmática em modelos para avaliação das características peso corporal aos 12 meses de idade, peso de velo sujo e diâmetro das fibras de lã de ovinos da raça Merino criados no Brasil, considerando os efeitos genético aditivo e permanente de meio maternos, além de verificar as interrelações entre esses efeitos e obter estimativas de herdabilidade para as três características.

\section{Material e Métodos}

O material usado neste trabalho, relativo a 1760 dados de produção (707 medidas de peso corporal e 703 de peso de velo sujo de fêmeas e 350 medidas de diâmetro das fibras de lã de ovinos da raça Merino com um ano de idade, nascidos no período de 1989 e 1993, e de 3645 informações de pedigree, foi cedido pela Associação Brasileira dos Criadores de Ovinos (ARCO). Os animais foram criados em uma só fazenda, de propriedade da Cabanha Azul S.A., município de Quaraí, Sudoeste do Rio Grande do Sul.

Feitas as análises de consistência dos dados, os arquivos apresentaram as seguintes informações: número do animal, sexo, número do pai e da mãe do animal, mês e anode nascimento de animal, pesode velo sujo (emum ano de crescimento), peso corporal, diâmetro das fibras de lãe idade do animal à tomada das medidas.

Após a tosquia, o velo sujo foi pesado e dele foi retirada uma amostra de aproximadamente $100 \mathrm{~g}$, coletada na região correspondente ao costado do animal. Esta amostra foi enviada para o laboratório de lãs da Universidade Federal de Pelotas para limpeza e medição do diâmetro das fibras de lã com o aparelho Air Flow, em mícrons. O peso corporal dos animais foi tomado após a tosquia.

A metodologia usada neste trabalho para a formação dos grupos de animais com o mesmo genótipo mitocondrial foi semelhante à relatada por SCHUTZ et al. (1992), em que os pedigrees dos animais foram investigados de forma a encontrar as ascendentes mais distantes em sua linhagem materna. Identificadas as ascendentes mais antigas, agruparam-se seus descendentes no que passou a ser chamado "linhagem citoplasmática". Entre as 41 linhagens citoplasmáticas identificadas, 28 foram utilizadas neste estudo, por possuírem números mínimos de descendentes com produção.

Todas as informações de parentesco direto foram aproveitadas, tanto do lado paterno quanto do materno. Os pais, em grande parte importados, somente em alguns casos possuíam informações de seus ascendentes. A estrutura final dos dados que foram utilizados nas análises encontra-se na Tabela 1 .

Inicialmente foram realizadas análises preliminares pelo método dos quadrados mínimos, com procedimentos incluídos no pacote estatístico SAS (SAS, 1995). Para todas as características mencionadas foram avaliados os efeitos de diversas fontes de variação, sendo mantidas nos modelos selecionados apenas as que apresentaram significância estatística $(\mathrm{P}<0,01)$. Entretanto, a variável aleatória linhagem citoplasmática foi mantida nos modelos selecionados, independente da significância estatística.

Os modelos selecionados para peso corporal, peso do velo sujo e diâmetro das fibras de lã foram, respectivamente, os seguintes:

$$
\text { em que }
$$$$
Y_{i j k l m}=\mu+C_{i}+E_{j}+A_{k}+L_{1}+e_{i j k l m}
$$

$\mathrm{Y}_{\mathrm{ijklm}}=$ peso corporal do animal $m$ filho do reprodutor $i$, nascido na estação $j$ e no ano $k$, pertencente à linhagem citoplasmática $l$; 
Rev. bras. zootec.

Tabela 1- Distribuição de ovinos da raça Merino para as características peso corporal, peso de velo sujo e diâmetro das fibras de lã, de acordo com o número de observações, número de pais, número de linhagens e o número mínimo de animais em cada linhagem citoplasmática

Table 1 - Distribution of Merino sheep for the traits body weight, greasy fleece weight and fiber diameter, according to the number of observations, number of sires, number of lineages and the minimum number of animals for each cytoplasmic lineage

\begin{tabular}{|c|c|c|c|c|c|}
\hline \multirow[b]{2}{*}{ Característica } & \multirow[b]{2}{*}{ Sexo } & \multicolumn{4}{|c|}{$\begin{array}{l}\text { Número } \\
\text { Number }\end{array}$} \\
\hline & & Observação & Pai & Linhagem & Mínimo ${ }^{1}$ \\
\hline Trait & Sex & Observation & Sire & Strain & Minimum $^{1}$ \\
\hline $\begin{array}{l}\text { Peso corporal, } \mathrm{kg} \\
\text { Body weight }\end{array}$ & Fêmeas & 707 & 45 & 28 & 10 \\
\hline $\begin{array}{l}\text { Peso do velo sujo, kg } \\
\text { Greasyfleece weight }\end{array}$ & Fêmeas & 703 & 45 & 28 & 10 \\
\hline $\begin{array}{l}\text { Diâmetro das fibras de lã, } \mu \\
\text { Fiber diameter, } \mu\end{array}$ & Machos & 350 & 37 & 27 & 5 \\
\hline
\end{tabular}

${ }^{1}$ Número mínimo de animais com produção em cada linhagem citoplasmática.

${ }^{1}$ Minimum number of observations for each cytoplasmic lineage.

$\mu \quad=$ média geral das observações;

$\mathrm{C}_{\mathrm{i}} \quad=$ efeito aleatório de reprodutor $(\mathrm{i}=1, \ldots, 45)$;

$\mathrm{E}_{\mathrm{j}} \quad=$ efeito fixo de estação de nascimento (codificado como $\mathrm{j}=1$, abril a junho $\mathrm{e} \mathrm{j}=2$, julho a outubro);

$\mathrm{A}_{\mathrm{k}} \quad=$ efeito fixo do ano de nascimento (codificado como $\mathrm{j}=1, \ldots, 5$ );

$\mathrm{L}_{1} \quad=$ efeito aleatório de linhagem citoplasmática $(1=1, \ldots, 28)$; e

$\mathrm{e}_{\mathrm{ijklm}}=$ efeito aleatório residual associado a cada observação.

$\mathrm{Y}_{\mathrm{ijklm}}=\mu+\mathrm{C}_{\mathrm{i}}+\mathrm{E}_{\mathrm{j}}+\mathrm{A}_{\mathrm{k}}+\mathrm{L}_{1}+\mathrm{b}\left(\mathrm{P}_{\mathrm{ijklm}}-\overline{\mathrm{P}}\right)+\mathrm{e}_{\mathrm{ijklm}}$ em que

$Y_{\mathrm{ijklm}}=$ peso do velo sujo ou diâmetro das fibras de lã do animal $m$ filho do reprodutor $i$, nascido na estação $j$ e no ano $k$, pertencente à linhagem citoplasmática $l$;

$\mu \quad=$ média geral das observações;

$\mathrm{C}_{\mathrm{i}}=$ efeito aleatório de reprodutor $(\mathrm{i}=1, \ldots, 45$ para peso do velo sujo e $\mathrm{i}=1, \ldots, 37$ para diâmetro das fibras de lã);

$\mathrm{E}_{\mathrm{j}} \quad=$ efeito fixo de estação de nascimento (codificado como $\mathrm{j}=1$, abril a junho $\mathrm{e} \mathrm{j}=2$, julho a outubro);

$\mathrm{A}_{\mathrm{k}} \quad=$ efeito fixo de ano de nascimento (codificado como $\mathrm{j}=1, \ldots, 5$ );

$\mathrm{L}_{1}=$ efeito aleatório devido à linhagem citoplasmática $(1=1, \ldots, 28$ para peso do velo sujo e $1=1, \ldots, 27$ para diâmetro das fibras de lã);

b = coeficiente de regressão linear do diâmetro das fibras de lã sobre o peso corporal (incluído apenas para $\mathrm{Y}_{\mathrm{ijklm}}=$ diâmetro das fibras de lã);

$\mathrm{P}_{\mathrm{ijklm}}=$ peso do animal em $\mathrm{kg}$;

$\overline{\mathrm{P}}=$ média do peso corporal; $\mathrm{e}$

$\mathrm{e}_{\mathrm{ijklm}}=$ efeito aleatório residual associado a cada observação.

A partir dos resultados dessas análises, foram obtidas estimativas dos componentes de variância e de herdabilidade pela correlação intraclasse entre meio-irmãos paternos para cada característica. Os erros-padrão para estas estimativas de herdabilidade foram calculados de acordo com SWIGER et al. (1964). Estas estimativas foram utilizadas como valores iniciais necessários às análises pelo método da máxima verossimilhança restrita (REML). Maiores detalhes sobre os resultados destas análises foram descritos por MORAIS (1998).

Para as análises pelo método da REML foi utilizado o aplicativo MTDFREML (BOLDMAN et al., 1995). O modelo mais completo, do qual derivaram os demais utilizados nesse trabalho, foi o seguinte:

$$
\mathrm{y}=\mathrm{X} \beta+\mathrm{Z}_{\mathrm{a}} \mathrm{a}+\mathrm{Z}_{1} 1+\mathrm{Z}_{\mathrm{m}} \mathrm{m}+\mathrm{Z}_{\mathrm{c}} \mathrm{c}+\mathrm{e}
$$

em que

$\mathrm{y}=$ vetor das observações (peso corporal, peso do velo sujo ou diâmetro das fibras de lã);

$\beta=$ vetor dos efeitos fixos (incluindo os mesmos efeitos fixos previamente selecionados nas análises preliminares);

$\mathrm{X}=$ matriz de incidência que relaciona os efeitos fixos ao y;

$\mathrm{a}=$ vetor dos efeitos aleatórios aditivos diretos;

1 = vetor dos efeitos aleatórios de linhagem citoplasmática;

$\mathrm{m}=$ vetor dos efeitos aleatórios aditivos maternos;

$\mathrm{c}=$ vetor dos efeitos aleatórios permanentes de meio materno;

$\mathrm{Z}_{\mathrm{a}}, \mathrm{Z}_{\mathrm{l}}, \mathrm{Z}_{\mathrm{m}}$ e $\mathrm{Z}_{\mathrm{c}}=$ matrizes de incidência que relacionam os efeitos a, $1, \mathrm{~m}$, e c, respectivamente, ao y;

$\mathrm{e}=$ vetor dos efeitos aleatórios residuais.

Para as análises, assumiu-se $\mathrm{E}(\mathrm{y})=\mathrm{X} \beta, \mathrm{E}(\mathrm{a})=$ 
$\mathrm{E}(\mathrm{l})=\mathrm{E}(\mathrm{m})=\mathrm{E}(\mathrm{c})=\mathrm{E}(\mathrm{e})=0$ e a seguinte estrutura básica da matriz de variância e covariância para os efeitos aleatórios:

$$
V\left[\begin{array}{c}
a \\
l \\
m \\
c \\
e
\end{array}\right]=\left[\begin{array}{ccccc}
A \sigma_{a}^{2} & 0 & A \sigma_{a m} & 0 & 0 \\
0 & I \sigma_{l}^{2} & 0 & 0 & 0 \\
A \sigma_{a m} & 0 & A \sigma_{m}^{2} & 0 & 0 \\
0 & 0 & 0 & I \sigma_{c}^{2} & 0 \\
0 & 0 & 0 & 0 & I \sigma_{e}^{2}
\end{array}\right]
$$

em que

$A$ é a matriz de coeficientes de parentesco entre os animais e $I$, uma matriz identidade. Os componentes de variância e covariância estimados foram:

$\sigma_{a}^{2}=$ a variância genética aditiva direta;

$\sigma_{m}^{2}=$ a variância genética materna direta;

$\sigma_{a m}=$ a covariância genética entre os efeitos direto e materno;

$\sigma_{1}^{2}=$ a variância da linhagem citoplasmática;

$\sigma_{c}^{2}=$ a variância dos efeitos permanentes de meio materno;

$\sigma_{\mathrm{e}}^{2}=$ a variância residual.

Considerou-se atingida a convergência quando os valores de logaritmo da razão de verossimilhança não se alteraram, de uma rodada para outra, até a quarta casa decimal e, além disso, quando a variância desse valor não foi maior que $10^{-9}$.

Para verificar a importância da inclusão da linhagem citoplasmática nos modelos, foi utilizado o teste de razão da verossimilhança. Segundo MYERS (1990), os valores de logaritmo da razão de verossimilhança representam o ajustamento do modelo utilizado para determinados dados. Estes valores são alterados, à medida que se acrescentam ou retiram um ou mais parâmetros, sendo maior para os melhores modelos. A alteração provocada pode ser um importante fator de verificação da importância do elemento acrescentado ou ignorado, uma vez que o modelo apresentará adequação de diferentes magnitudes. Estas diferenças deverão ser significativamente diferentes de zero para representar alguma importância; esta significância é testada pela razão das verossimilhanças. A razão é representada por $2 \ln \left[\mathrm{L}\left(\hat{\beta}_{2}\right) / \mathrm{L}(\hat{\beta})\right]$ e é assintoticamente distribuída $\operatorname{como} \chi^{2}$ com graus de liberdade iguais à diferença em número de parâmetros dos dois modelos, em que L é o valor da máxima verossimilhança em $\hat{\beta}_{2}$ (modelo reduzido) e $\hat{\beta}$ (modelo mais completo).

\section{Resultados e Discussão}

Os coeficientes de variação, o coeficiente de determinação e o nível de significância para o efeito de linhagem citoplasmática, encontrados nas análises iniciais, estão representados na Tabela 2. Os coeficientes de variação foram baixos, especialmente para diâmetro das fibras de lã, cuja medição é laboratorial. Como os animais utilizados neste experimento foram muito homogêneos, mesmo sexo, aproximadamente a mesma idade e criados no mesmo ambiente, pode-se considerar normais estes valores. Os coeficientes de determinação, indicadores da capacidade do modelo em explicar as variações, também apresentaram baixos valores. Este problema pode ser atribuído às variáveis que puderam ser consideradas e à opção de trabalhar com modelos mais compactos, em que somente as variáveis com efeito significativo $(\mathrm{P}<0,01)$, excetuandose a linhagem citoplasmática, foram mantidas.

Ainda, por meio da Tabela 2, observou-se que, entre as três características nas quais o efeito de linhagem citoplasmática foi pesquisado, peso corporal foi a que apresentou esse efeito mais próximo da significância $(\mathrm{P}=0,097)$.

Os componentes de variância estimados pelo método da REML para os diversos modelos testados para as características peso corporal, peso de velo sujo e diâmetro das fibras de lã são apresentados na Tabela 3.

A variância dos efeitos residuais decresceu na medida em que os modelos se tornaram mais completos para todas as características, possivelmente porque parte da variação que estava sendo computada para o resíduo foi decorrente dos efeitos aditivo materno, permanente de meio materno e de linhagem citoplasmática. SOUTHWOOD et al. (1989), embora não tenham considerado o efeito permanente de meio materno, chamaram a atenção para o fato de que o uso de um modelo inadequado pode levar à falsa partição das variâncias.

Ainda em relação à variância residual, é interessante notar que, quando o efeito aditivo materno foi incluído no modelo sem linhagem citoplasmática e sem efeito permanente de meio materno, houve redução de $6 \%$ na variância residual, visualizada na comparação entre os modelos I e III para peso corporal (Tabela 3). Ao mesmo tempo, para essa mesma característica, o efeito de linhagem, quando incluído isoladamente ou em conjunto com o efeito 
Rev. bras. zootec.

Tabela 2 - Coeficientes de variação e de determinação e nível de probabilidade para o efeito de linhagem citoplasmática $(P)$ nos modelos selecionados para análise das características peso corporal, peso de velo sujo e diâmetro das fibras de lã

Table 2 - Coefficients of variation, coefficients of determination and probability level $(P)$ for the effect of cytoplasmic lineage in selected models for the traits body weight, greasy fleece weight and fiber diameter

\begin{tabular}{lccc}
\hline $\begin{array}{l}\text { Característica } \\
\text { Trait }\end{array}$ & $\mathrm{CV}$ & $\begin{array}{c}\text { Coeficiente de } \\
\text { determinação, \% } \\
\text { Coefficient ofdetermination }\end{array}$ & $\mathrm{P}$ \\
\hline $\begin{array}{l}\text { Peso corporal, kg } \\
\begin{array}{l}\text { Bodyweight } \\
\text { Peso do velo sujo, kg }\end{array}\end{array}$ & 15,88 & 56 & 0,097 \\
$\begin{array}{l}\text { Greasyfleece weight } \\
\text { Diâmetro das fibras de lã, } \mu\end{array}$ & 6,60 & 40 & 0,654 \\
Fiber diameter & & & 0,149 \\
\hline
\end{tabular}

Tabela 3 - Estimativas de componentes de (co)variância obtidos pelo método REML sob diferentes modelos e testes de razão das verossimilhanças entre modelos incluindo ou não linhagem citoplasmática para as características peso corporal, peso de velo sujo e diâmetro das fibras de lã

Table 3 - REML (co)variance components estimates for different models and likelihood ratio test between the models including or not cytoplasmic lineage for the traits body weight, greasy fleece weight and fiber diameter

\begin{tabular}{|c|c|c|c|c|c|c|c|c|}
\hline \multirow[t]{2}{*}{$\begin{array}{l}\text { Modelo } \\
\text { Model }\end{array}$} & \multicolumn{7}{|c|}{$\begin{array}{l}\text { Componentes de (co)variância }{ }^{1} \\
\text { (Co) variance components }\end{array}$} & \multirow{2}{*}{$\begin{array}{l}\text { Teste de razão das } \\
\text { verossimilhanças }{ }^{3} \\
\text { Likelihood ratio test }\end{array}$} \\
\hline & $\sigma_{\mathrm{p}}^{2}$ & $\sigma_{\mathrm{e}}^{2}$ & $\sigma_{\mathrm{a}}^{2}$ & $\sigma_{\mathrm{m}}^{2}$ & $\sigma_{c}^{2}$ & $\sigma_{\mathrm{am}}$ & $\sigma_{1}^{2}$ & \\
\hline \multicolumn{9}{|c|}{ Peso corporal, $\mathrm{kg}^{2}$ (Body weight $)$} \\
\hline 1 & 10,542 & 6,628 & 3,913 & - & - & - & - & \\
\hline 2 & 10,508 & 6,691 & 3,746 & - & - & - & 0,071 & $2-1=0,35^{\mathrm{ns}}$ \\
\hline 3 & 10,610 & 6,259 & 2,768 & 2,569 & - & $-0,987$ & - & \\
\hline 4 & 10,595 & 6,269 & 2,781 & 2,577 & - & $-1,077$ & 0,045 & $4-3=0,12^{\mathrm{ns}}$ \\
\hline 5 & 10,354 & 5,753 & 2,721 & 0,817 & 1,438 & $-0,375$ & - & \\
\hline 6 & 10,344 & 5,753 & 2,728 & 0,819 & 1,450 & $-0,461$ & 0,054 & $6-5=0,18^{\mathrm{ns}}$ \\
\hline \multicolumn{9}{|c|}{ Peso de velo sujo, $\mathrm{kg}^{2}$ (Greasy fleece weight) } \\
\hline 1 & 0,283 & 0,228 & 0,055 & - & - & - & - & \\
\hline 2 & 0,283 & 0,229 & 0,055 & - & - & - & 0,000 & $2-1=0,00^{\mathrm{ns}}$ \\
\hline 3 & 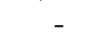 & 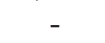 & - & - & - & - & - & \\
\hline 4 & 0,283 & 0,229 & 0,055 & 0,000 & - & - & 0,000 & $4-2=0,00^{\mathrm{ns}}$ \\
\hline 5 & 0,282 & 0,218 & 0,051 & 0,000 & 0,014 & 0,000 & - & \\
\hline 6 & 0,284 & 0,207 & 0,069 & 0,002 & 0,186 & $-0,013$ & 0,000 & $6-5=0,67^{\mathrm{ns}}$ \\
\hline \multicolumn{9}{|c|}{ Diâmetro das fibras de lã, $\mu^{2}$ (Fiber diameter) } \\
\hline 1 & 2,030 & 1,699 & 0,331 & - & - & - & - & \\
\hline 2 & 2,030 & 1,699 & 0,331 & - & - & - & 0,000 & $2-1=0,00^{\mathrm{ns}}$ \\
\hline 3 & 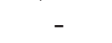 & 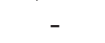 & - & - & - & - & - & \\
\hline 4 & 2,030 & 1,700 & 0,332 & 0,000 & - & 0,000 & 0,000 & $4-2=0,00^{\mathrm{ns}}$ \\
\hline 5 & 2,030 & 1,700 & 0,330 & 0,000 & 0,000 & 0,000 & - & \\
\hline 6 & 2,031 & 1,700 & 0,332 & 0,000 & 0,000 & 0,000 & 0,000 & $6-5=0,00^{\mathrm{ns}}$ \\
\hline 7 & 1,902 & 1,502 & 0,400 & 0,000 & 0,000 & 0,000 & - & \\
\hline 8 & 1,902 & 1,502 & 0,400 & 0,000 & 0,000 & 0,000 & 0,000 & $7-6=0,00^{\mathrm{ns}}$ \\
\hline \multicolumn{9}{|c|}{$\begin{array}{l}1 \sigma_{\mathrm{p}}^{2}, \sigma^{2}{ }_{\mathrm{e}}, \sigma_{\mathrm{a}}^{2}, \sigma^{2}{ }_{\mathrm{m}}, \sigma_{\mathrm{c}}^{2}, \sigma_{\text {am }} \text { e } \sigma^{2}{ }_{\mathrm{I}}=\text { componentes de variância fenotí́ica total, residual, aditivo direto, } \\
\text { aditivo materno, permanente de meio materno, componente de covariância entre os efeitos aditivos direto e materno } \\
\text { e componente de variância de linhagem citoplasmática, respectivamente. }\end{array}$} \\
\hline \multirow{2}{*}{\multicolumn{9}{|c|}{ 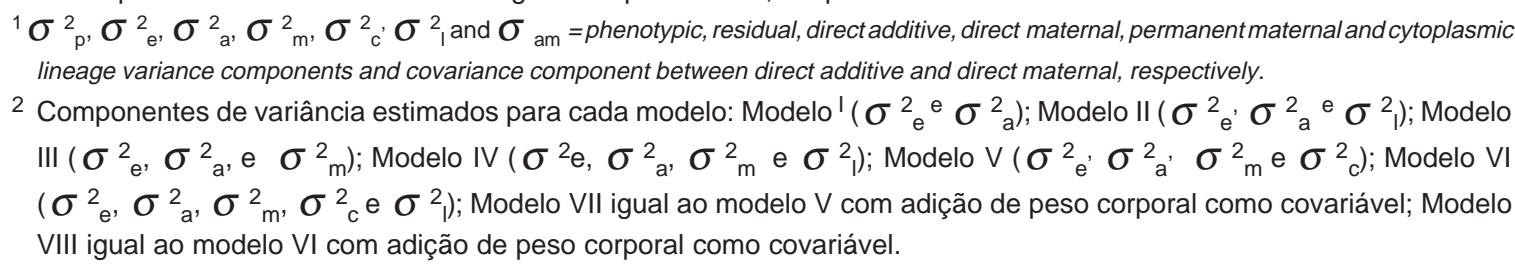 }} \\
\hline & & & & & & & & \\
\hline \multicolumn{9}{|c|}{ 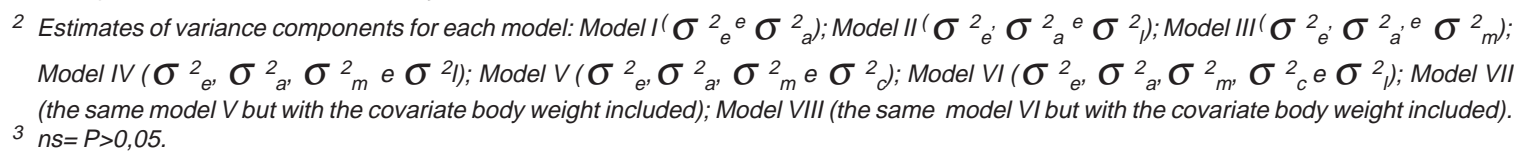 } \\
\hline
\end{tabular}


aditivo materno, provocou pequeno aumento na variância residual. Já a inclusão do efeito permanente de meio materno foi a que provocou maior alteração na variância residual de peso corporal, tendo reduzido a mesma próximo de $9 \%$. Curiosamente, a inclusão deste efeito aumentou ligeiramente a variância do efeito aditivo materno e consideravelmente a variância de linhagem citoplasmática (próximo a 20\%), na comparação dos modelos IV, V e VI (Tabela 3).

Para o peso de velo sujo pôde ser observada a mesma tendência apresentada para peso corporal em relação ao efeito permanente de meio materno, porém de forma menos intensa. A interdependência dessas estimativas de componentes de variância pode ser atribuída a confundimentos parciais entre eles. SOUSA (1997) recomenda cautela no estudo dos efeitos permanente de meio materno e aditivo materno conjuntamente, justamente pela possibilidade de haver esse confundimento. No presente estudo o efeito da linhagem citoplasmática sobre o peso corporal foi menos aparente na presença do efeito aditivo materno, indicando que os modelos nos quais este efeito não foi incluído poderiam apresentar estimativas inflacionadas da variância de linhagem citoplasmática.

Os valores do componente de variância de linhagem citoplasmática foram muito baixos para a característica peso corporal, tendo seu valor diminuído em cerca de $37 \%$ (modelo II vs. modelo IV, Tabela 3), quando se considerou o efeito materno no modelo. Para peso de velo sujo e diâmetro médio das fibras de lã, os valores não foram diferentes de zero, enquanto a variância fenotípica permaneceu praticamente inalterada com a inclusão do efeito de linhagem citoplasmática.

Pelo teste da razão das verossimilhanças, as diferenças entre os modelos que consideraram e os que omitiram os efeitos de linhagem não foram significativas para as três características, o que eqüivale a dizer que não seria justificadaa inclusão de linhagem citoplasmática nos modelos para avaliação das características peso corporal, peso de velo sujo e diâmetro médio das fibras de lã em ovinos da raça Merino com um ano de idade. Nota-se que, para peso de velo sujo e diâmetro das fibras de lã, o segundo teste realizado (Tabela 3) diz respeito à significância do efeito aditivo materno, modelo IV menos o modelo II, em razão da impossibilidade de convergência para o modelo III.

Para peso do velo sujo e diâmetro das fibras de lã, também não foram diferentes os modelos que incluíram e os que não incluíram os efeitos aditivos maternos e permanentes de meio maternos. Entretanto, para peso corporal, houve diferenças significativas
$(\mathrm{P}<0,05)$ entre os dois tipos de modelos. Estes resultados estão de acordo com os encontrados por MORTIMER e ATKINS (1994), para peso corporal e diâmetro das fibras de lã, mas contrastam com os obtidos para peso de velo sujo. De forma semelhante aos achados deste estudo, VAEZ TORSHIZI et al. (1996) encontraram efeito aditivo materno significativo para o peso corporal de Merinos aos 10 meses de idade. Também SNYMAN et al. (1996) encontraram efeitos aditivos maternos significativos para peso corporal e peso de velo sujo mas não para diâmetro das fibras de lã. Todos esses autores trabalharam com metodologia REML.

No Brasil, SOUSA (1997) encontrou decréscimo na importância dos efeitos maternos sobre o peso de ovinos da raça Santa Inês, entre a desmama e os 196 dias de idade, e argumentou que esses efeitos diminuíram à medida em que a cria se tornou mais independente da mãe. Como no presente trabalho a média de idade dos animais foi de um ano de idade, os efeitos maternos para as três características podem ter sido ainda mais reduzidos.

As conseqüências destas interrelações entre os efeitos aditivo materno e permanente de meio materno podem ser melhor visualizadas na Tabela 4, em que são apresentados os efeitos genético aditivos direto e materno, efeito permanente de meio materno e efeito de linhagem citoplasmática como proporção da variância fenotípica total, para cada característica e modelo testado, além das correlações genéticas entre os efeitos aditivos direto e materno. Estas correlações, quando diferentes de zero, foram todas negativas. MORTIMER e ATKINS (1994) encontraram valores negativos da mesma correlação para peso de velo sujo e diâmetro das fibras de lã, mas não para o peso corporal.

A associação entre os efeitos aditivo materno e permanente de meio materno é bastante controversa. Por exemplo, SNYMAN et al. (1996) obtiveram correlações negativas entre os efeitos aditivo materno e permanente de meio materno para peso de velo sujo e positivas para peso corporal, enquanto VAEZTORSHIZI et al. (1996) verificaram valores negativos para esta última característica. Entretanto, ROBINSON (1996b), trabalhando com dados simulados, encontrou algumas das razões que poderiam explicar essas correlações negativas e alertou para o fato de que as correlações entre os valores genético direto e materno refletem de forma significativa a estrutura de dados.

Apesar de, no presente estudo, nenhum dos modelos ter demonstrado efeito significativo de linha- 


\section{Referências Bibliográficas}

BELL, B.R., McDANIEL, B.T., ROBISON, O. W. 1985. Effects of cytoplasmic inheritance on production traits of dairy cattle. J. Dairy Sci., 68:2038-2051.

BOLDMAN, K.G.,KRIESE,L.A., VAN VLECK, L.D. et al. 1995. A set of programs to obtain estimates of variances and covariances. A manual for use of MTDFREML. Department of Agriculture, Agricultural Research Service, USA.

BROWN, D.R., KOEHLER, C.M., LINDBERG, G.L. et al. 1989. Molecular analysis of cytoplasmic genetic variation in Holstein cows. J. Anim. Sci., 67:1926-1932.

HIENDLEDER, S., HECHT, W., DZAPO, V. et al. 1991. Ovine mitochondrial DNA: restriction enzime analysis, maping and sequencing data. Animal Genetics, 23:151-160.

HIENDLEDER, S. 1996. Molecular caracterization of the sheep mitochondrial genome. J. Anim. Breed. Genet., 113:293-302.

HUIZINGA, H. A., KORVER, S., McDANIEL, B.T. et al. 1986. Maternal effects due to cytoplasmic inheritance in dairy cattle. Influence on milk production and reproduction traits. Lvst. Prod. Sci., 15:11-26.

KIRKPATRICK, B.W., DENTINE, M.R. 1988. An alternative model for additive and citoplasmic genetic and maternal effects on lactation. J. Dairy Sci., 71:2502-2507.

LIMA, F.A.M. Estudo genético-quantitativo das produções parciais e produção total de leite e do desenvolvimento ponderal de caprinos no Nordeste Semi-Árido do Brasil. Belo Horizonte, MG: Escola de Veterinária da UFMG, 1994. 129 p. Tese (Doutorado em Ciência Animal) - Universidade Federal de Minas Gerais, 1994.

LOI, P., BOYAZOGLU, S., GALLUS, M. et al. 1997. Embryo cloning in sheep: work in progress. Theriogenology, 48:1-10.

MIKAMI, H., ONISHI, A., KOMATSU, M. et al. 1991. Relationship between mitochondrial DNA variation and heterosis in cytocrome coxidase activity in the mouse. Anim. Sci. Techn., 9(62):822-828.

MORAIS, O.R. Efeito de linhagem citoplasmática em características de produção em ovinos da raça Merino. Belo Horizonte, MG: Escola de Veterinária da UFMG, 1998. 93p. Dissertação (Mestrado em Zootecnia) - Universidade Federal de Minas Gerais, 1998.

MORTIMER, S.I., ATKINS, K. D. Direct additive and maternal genect effects on wool production of Merino sheep. In: WORLD CONGRESS ON GENETICS APPLIED TO LIVESTOCK PRODUCTION, 5, 1994, Guelph, Canadá. Proceedings... Guelph, WCGALP, 1994, v. 18, p.103-106.
MYERS, R.M. 1990. Classical and modern regression with applications. 2 ed. Boston : PWS-Kent Publishing Company. p.322-326.

ROBINSON , D.L. 1996a. Estimation and interpretation of direct and maternal genetics parameters for weights of Australian Angus cattle. Lvst. Prod. Sci., 45:111-122.

ROBINSON, D.L. 1996b. Models which might explain negative correlations between direct and maternal effects. Lvst. Prod. Sci., 45:111-122.

SAS 1995. User's Guide Statistics. Version 6.10 edition. Cary, NC: SAS Institute Inc. 956p.

SCHUTZ, M.M., FREEMAN, A.E., BEITZ, D.C. et al. 1992. The importance of maternal lineage on milk yield traits of dairy cattle. J. Dairy Sci., 75:1331-1341.

SNYMAN, M.A., OLIVIER, J.J., OLIVIER, W.J. 1996. Variance components and genetic parameters for body weight and fleece traits of Merino sheep in an arid environment. S. Afr. J. Anim. Sci., 26(1):11-14.

SOUSA, W.H. Aplicação de modelos lineares e não lineares em características de reprodução, sobrevivência e crescimento de ovinos deslanados da raça Santa Inês. Belo Horizonte, MG: Escola de Veterinária da UFMG, 1997. 131p. Tese (Doutorado em Ciência Animal) - Universidade Federal de Minas Gerais, 1997.

SOUTHWOOD, O.I., KENNEDY, B.W., MEYER, K. et al. 1989. Estimation of additive maternal and cytoplasmic genetics variances in animal models. J. Dairy Sci., 72:3006-3012.

SWIGER, L.A., HARVEY, W.R., EVERSON, D. O. et al. 1964. The variance of intraclass correlation involving groups with one observation. Biometrics, 20(4):818-824.

VAEZ TORSHIZI, R., NICHOLAS, F.W., RAADSMA, H.W. 1996. REML estimates of variance and covariance components for production traits in Australian Merino sheep, using na animal model. Aust. J. Agric. Res., 47:1235-1249.

VILLALTA, M., FERNANDEZ-SILVA, P., BELTRAN, B. et al. 1992. Molecular characterization of sheep mitochondrial DNA. Curr. Genet., 21:235-240.

Recebido em: 11/09/98

Aceito em: 15/03/99 